\title{
Research on Moral Education Affinity from the Perspective of Psychology
}

\author{
Zhang Jing \\ (Hohai University; Nanjing; anjingor@126.com) \\ ORCID: 0000-0002-8809-3357

\section{Li Suting} \\ (Fudan University; Shanghai; $1284757496 @ q q . c o m)$ \\ ORCID: 0000-0001-5704-0917
}

\section{Introduction}

Morality is the code and norm prescribing how people should live together and behave. With the development of the economy and globalization, people pay more and more attention to money and material objects, but neglect spiritual and moral construction. Therefore, the study of moral education is particularly important at present, and there are many factors influencing the effect; among these, the affinity of moral education has a very important impact on the smooth development of moral education activities and on the improvement of educational effectiveness.

This paper analyzes the formation of moral education affinity from the perspectives of educator and educatee, covering the psychological mechanism and psychological process, and puts forward the main ways for cultivating moral education affinity. It is hoped that this study will be used for reference by other moral education researchers and moral educators (Noonan 2019; Ren 2016; Arends 2005).

Moral education affinity means that, during the process of moral education, moral educators, with their own unique qualities, generate the force of closeness and combination, the capacity of psychological demand, the forces of infection, cohesion, attraction and appeal, by optimizing the environment of moral education, innovating its concepts and content, and improving the methods and evaluation mechanisms for this subject. It shows the relationship between the educators and educatees in the process of moral education, the psychological atmosphere and the process order in the state of affinity. Manifesting this state in education-related cognitive, verbal-dialogical and other psycho-motoric activities would increase educators' performance and facilitate education's formative effect on educatees' sociomoral development. Therefore, it is necessary to discuss moral education affinity from the perspective of the psychological 
mechanism and psychological process.

\section{The Psychological Mechanism on which the Moral Education Affinity Depends}

The process of moral education is that in which, under the guidance of educators, the educatees improve their moral cognition, cultivate moral emotions, exercise moral will, and form the continuity of moral quality and behavior, based on the needs of their morality and psychological quality. During the process of generating moral education affinity, the initiative of moral educators must be based on the psychological acceptance of the educatees. Therefore, the discussion on the psychological mechanism by which the moral education affinity is generated must start from the educatees and be realized in the interaction between the educator and the educatee (Ren 2016; Liu, Savitz-Romer, Perella, Hill, \& Liang 2018; Li Qu \& Qu Yang 2019).

\subsection{The needs and emotions of educatees: the dynamic mechanism of affinity generation}

A need is the psychological tendency of an individual to feel a certain lack and strive to get satisfaction. It is the reflection of the requirements of the individual and the external living conditions in the mind. A. H. Maslow's psychology claims individual needs to be the source and foundation of individual initiative and motivation (Maslow 1943). The stronger the individual needs, the higher the motivation. Therefore, when carrying out moral education activities, educators should firstly consider the needs of the educatees, and let the educatees feel the care of the educators, so as to effectively enhance the willingness of the educatees to accept the guidance of their thoughts and behaviors, which is the primary condition for generating the affinity for moral education.

Emotion is the psychological intentionality taken by people towards objective things, and this intentionality itself is a kind of behavioral motivation. In moral education activities, emotion includes two aspects. Firstly, the attitude and experience of the educatees to the moral concepts and moral norms required by the society, which permeates through all aspects of education activities, in an implicit way; secondly, the attitudes of educatees towards educators; the process of education is itself upheld by love, rejection or aversion and other emotional tendencies. Both aspects have a profound influence on the development of educational activities and the acceptance, selection, processing and application of information by educatees. The emotion of the educatees is not innate, nor can it be realized through knowledge acquisition or compulsion. It must be understood and cultivated by educators. Firstly, educators should base their approaches on the emotional characteristics of educatees. Educational activities should be able to change direction and constantly adjust educational content to meet the emotional requirements of educatees. Secondly, educators should adjust the emotional state of educatees in 
time. The emotional state of the educatees affects not only the dominant orientation of information reception, but also stimulates its acceptability. When the educatees are in a negative emotional state, their perception and understanding of the received information will be negative attitude. In contrast, when they are in a positive emotional state, this can keep the information receiving system open and foster an amiable and accepting attitude towards information. Therefore, the educators should take the initiative to help the educatees to adjust their bad mood, if they have one, and to improve their affective self-regulation. Thirdly, educators should actively promote emotional integration with educatees. The emotions of individuals are affected to varying degrees by the emotions of others, especially those close to them. Educators' concern, understanding and trust in the educatees will make the educatees emotionally satisfied and make them feel the appeal of moral education affinity. It can be seen that emotion is indispensable to moral education. Without emotional attention to, and emotional regulation of, the educatees, educational activities will be a process without vitality, of mechanization, and moral education will naturally be difficult to produce effective appeal and affinity (see also Roeser, Eccles, \& Sameroff 2017). And last but not least, improving affect regulation in learners and also their reciprocal emotional relations (Chapman \& McGregor 2002) - which is related to the reciprocal emotional relations between teachers and learners - may stimulate learners' motivation for learning (Deci \& Ryan 1985). A specific moral emotion which facilitates the moral education process - and also moral socialization - was called empathy by Habermas. One of his early works is worth of quoting here:

moral feelings play a role not merely in the application of moral norms, but also in their grounding. Empathy, as the very least - in other words, the capacity to transport oneself by means of feeling across cultural distance into alien and prima facie incomprehensible life conditions, patterns of reaction, and interpretative perspectives - is an emotional precondition for the ideal taking over the roles, which requires each person to adopt the standpoint of all the others. To see something from a moral point of view means that we do not elevate our own understanding of the world and our self-understanding to the status of criteria for the universalization from the perspective of all others. This demanding cognitive achievement would scarcely be possible without that generalized sympathy which becomes sublimated into a capacity for fellow feeling, and points beyond our emotional ties to those closest to us, opening our eyes to 'difference' - in other words, to the individuality and autonomius significance of the other who remains in his or her otherness (Habermas 1985, 269-270).

\subsection{The will of educatees: the maintenance mechanism of affinity}

In terms of the moral education affinity, the function of will is to adjust and integrate the cognition and emotion of the educatees, so that they can maintain a certain enthusiasm in the process of communicating with educators and while receiving education, and thus maintain the psychological harmony in the educational process. The will of the educatees is not formed spontaneously, but is gradually cultivated under the effective guidance of educators through the comprehensive function of cognitive activities and emotional 
activities in the acceptance of moral education. Firstly, educators should pay attention to the cultivation of educatees' awareness. The goal consciousness can promote the cultivation of their will and enhance the likelihood that they will receive educational information. Secondly, educators should promote educatees' awareness of the link to will cultivation. The process of the educatees receiving moral education information includes the link to will cultivation. If they fail to form a certain identification with it, the educatees will generate a resistant psychology and hinder the formation of affinity. In moral education activities, educators should make the educatees feel the importance of willpower in overcoming internal conflicts, interference and external obstacles according to his actual ability and inner expectation, so as to consciously hone their perseverance. In the process of helping educatees to cultivate their wills, educators guide them to establish goals, care about their development requirements, and give them effective help, which is exactly what is needed to make educatees feel the moral education affinity so that the affinity can be maintained.

\subsection{Psychological compatibility: the safeguard mechanism of affinity}

Psychological compatibility refers to the psychological state in which educators and educatees are accepted by each other in terms of ideas, moral qualities, words and deeds, etc., so as to form a harmonious and consistent psychological state. Emotional harmony and psychological harmony help educatees to have a sense of dependence on educators, making them willing to accept the guidance of educators and have a positive understanding of educational content. In the process of communication, the educatees can feel the educators' care and help, understand the educators' good intentions, and fully trust the educators, which will naturally generate moral education affinity. To be specific, firstly, when the two sides have similar or relatively consistent identification with regard to moral cognition, they will feel closely connected with each other. However, there the educatees may feel negative resistance to the educator and the educational content. Therefore, educators should give positive guidance to the educatees. Secondly, if the educators have good moral character and personal accomplishments, they will attract and inspire educatees, so that they are willing to communicate with them actively and accept guidance, so as to persuade people by virtue. Thirdly, effective communication is indispensable for educators and educatees to achieve a state of psychological communion. Only through communication can educators understand educatees and their true thoughts and moral level, and then guide their incorrect views. In addition, educators should also take the initiative to find a common language with educatees, causing emotional resonance. In contrast, if the educators are indifferent and condescending, they will surely make educatees stay at a respectful distance, create psychological estrangement, and even generate antagonistic feelings and rebellious psychology (Scherzinger \& Wettstein 2019; Hasija, Liou, \& Ellstrand 2020). 
1.4 Learning the psychology of educatees: the strengthening mechanism of affinity

For educatees, moral education is a kind of learning activity, that is, through learning, they come to accept the influence and education of the society, forming the moral concepts and moral norms required by society, and transforming them into behavior. Their learning psychology will directly affect the effect of education affinity, if educators can effectively stimulate the motivation to learn, help the educatees to discover their learning autonomy, pay attention to strengthening the learning effect of educatees, educatees will be full of enthusiasm and of the feeling of learning knowledge. In this learning process, educators and educatees are in a harmonious state of frequent communication and interaction, and the educatees naturally feel the moral education affinity. As a mechanism for strengthening affinity, the key to learning psychology lies in the learning autonomy and initiative of the educatees. In moral education, educators should take the educatees as an active individual, emphasize their central position in learning activities, and explore their autonomy. Firstly, the educatees should be guided to realize the learning significance of moral education. Educators should carry out reform and innovation from the aspects of educational concepts, educational content, educational methods and educational means, so as to make the educatees realize that moral education is of great significance to the formation, healthy growth and overall development of their moral character, and thus the educatees become active learners. Secondly, self-education can be realized through exploration and learning. For the educatees, "self-education is a process of awakening their moral consciousness, stimulating their internal motivation mechanism, and coordinating their balance with the outside world and self-improvement. Self-education is the highest purpose of moral education. Individuals who can conduct self-education can make correct choices and adjustments in the face of numerous moral problems, and then face moral problems with a correct attitude" (Pinto \& Poornananda 2017, 9-14).

\section{The Psychological Process of the Generation of Moral Education Affinity}

The generation of moral education affinity is a psychological process in which educators and educatees influence each other. Generally speaking, this psychological process is parallel to the educational process in which educators take the initiative to use the law of interpersonal attraction and the principle of psychological effect, constantly promote the attitude change of educatees, and form an amiable interpersonal relationship and psychological atmosphere in the psychological exchange and interaction between themselves and educatees (Chapman \& McGregor 2002).

\subsection{Educators' proactive interpersonal attraction}

Interpersonal attraction refers to the emotional intimacy between individuals and others in the process of interpersonal communication. It is a form of affirmation 
in the interpersonal relationship, and its dominant component is human emotion. In moral education, educators should make full use of the law of interpersonal attraction to increase the emotion with educatees, build a good harmonious interpersonal relationship, and make moral education full of affinity. To be specific, firstly educators deepen their affection for educatees according to the law of proximity. The interaction between educators and educatees should not be limited to the classroom, but also should involve more contact after class. The content of communication should not be limited to study, but should also care about their thoughts, life and other aspects. Only by increasing the frequency and depth of communication can the two sides deepen communication, enhance understanding and deepen emotions in the process of communication. Secondly, educators realize the reasonable integration of moral education according to the law of similarity. Educators should be good at finding similarities between the two parties to arouse the positive emotions of the educatees. For example, through common interests and hobbies, life experiences, regions, etc. as the entry point for communication, with a certain basis for emotional exchange, the development of moral education work truly reflects the blend of emotion and reason in education, and avoids the perception of ostentation and the feeling of distaste caused by rigid preaching. Finally, educators inspire educatees with their heart, according to the law of equality. The emotional communication between people and their efforts are equal. When educators sincerely respect, understand and care for the educatees, the latter will feel and be inspired by the other party's behavior, and then accept the education wholeheartedly.

\subsection{The application of positive psychological affects}

Psychological affects is a common psychological phenomenon and law in social life. It is a causal reaction or chain reaction caused by the action of a certain person or thing on the corresponding change of others or things. It has both positive and negative significance. Positive psychological effects can help people to use the law, improve the efficiency of study and work, dissolve psychological pressure, etc. Negative psychological effects will make people produce bad psychological responses, leading to cognitive bias and wrong behavior. Therefore, in moral education, educators should be good at using the positive role of psychological effect and overcoming its negative influence, which is an effective measure for promoting the generation of moral education affinity. Firstly, educators should make good use of the Primacy effect and Recency effect. The Primacy effect is the first impression that people form when they first come into contact with someone or something that affects their later behavior and evaluation. The Recency effect, also known as the serial position effect, refers to the phenomenon that people remember the end of a series of things better than the middle. In moral education, educators should evaluate educatees after in-depth observation and understanding, so as to avoid one-sided educative assumptions that lead to emotional damage and psychological estrangement among educatees. At the same time, educators should give full play to the positive role 
of the two, especially in the image of educators and educational content. For example, when moral educators first meet educatees, they can make careful preparations in terms of appearance, speech and behavior, and communication content, so as to make a good first impression on the other side and encourage them to have a positive attitude of being inspired and willing to accept actively, thus laying a good emotional foundation for further work. In addition, some educatees do not attach importance to moral education, believing that moral education has no connection with reality and is a kind of empty preaching. This requires educators, through their own personal charm and superb professional level, to use the Recency effect to change educatees' preconceptions, so that they can understand and experience the depth of moral education and its content, and take the initiative to accept and get close to moral education. Secondly, educators have taken advantage of the Pygmalion effect and the labeling effect. The Pygmalion effect, also known as Rosenthal effect and Expectation effect, refers to the expectation through a strong psychological hint that behavior is expected to meet certain requirements. In moral education, when educators regard educatees as having potential and as excellent people, and often encourage and praise them, positive psychological hints will be given. Educators give educatees some positive, affirmative, encouraging phrases, such as "you can do it," "you're doing a good job," "you're good," etc., so as to stimulate their enthusiasm and potential. However, if educators don't care about or even ignore the feelings of educatees, or often label them with negative labels, such as "you can't do anything well" and "you are stupid," they will have a sense of loss and inferiority, thus lowering their self-esteem, self-confidence and enthusiasm, and even misleading them to develop in a bad direction. The above two kinds of psychological effects have a certain guiding effect. Educators should maker their expectations clear to educatees, and use more positive phrases, so that educatees can feel the moral education affinity.

\subsection{Change of the educatee's attitude}

The process in which educators guide educatees to form the moral codes and social behavior required by the society is actually the process in which educators urge educatees to form the right attitude or change their wrong attitude. Such change should begin with changing the attitude of educatees towards educators and educational content. Educators can use the Cognitive Dissonance Theory, Cognitive Balance Theory or Cognitive Persuasion Theory to change the attitude of educatees, their cognition and some incorrect thoughts. So that the moral code of conduct required by society can be transformed into good character and good behavior habits of educatees. The change of the educator's attitude towards educatees plays a decisive role. Firstly, the prestige of the educator is the key factor that determines the change of attitude of the educatees. Only when the educatees feel that the educator is amiable, respectable and credible will they be convinced of his character and knowledge, then they will accept the professor's content, and then internalize it into their own moral concept, and finally externalize 
it into behavior. Secondly, the good moral quality of educators plays a subtle role in demonstrating for educatees. In carrying out moral education activities, educators set a good example for educatees through their ideals and beliefs, thoughts and feelings, words and deeds, and urge them to follow suit, adjust and correct their thoughts and behaviors. It can be seen that the process of changing the attitude of educatees is also the process of generating the moral education affinity.

\subsection{The psychological exchange and interaction between educators and educatees}

Psychological exchange is not only an important factor for the success of interpersonal communication, but also an important psychological principle for the generation of moral education affinity. Educators should actively empathize with the role of educatees in daily life and various educational activities. According to educatees' identity, status and environment, educators should have psychological experience of the educatees' position, and have a comprehensive and understanding of their thoughts, needs, emotions and other psychological states. This is not only targeted at carrying out moral education, but also at encouraging more understanding and feelings in educatees. In this way, educatees will be forced to consider the problem from the position of educators and experience their mentality and emotion. This will increase the understanding and feelings of educatees for the educator, eliminate the initial defensive feelings or resistance, and help them to accept the information conveyed by educators with a positive mood and a trusting attitude. It can be seen that psychological exchange can make educators and educatees trust each other emotionally and accept each other psychologically, thus realizing the moral education affinity.

The generation of affinity for moral education is also a process of psychological interaction between educators and educatees. The process of moral education is the psychological interaction between educators and educatees. Educators play a leading role in exerting moral influence on educatees in accordance with social requirements. However, the educatees are not passively influenced by education. They have already formed their own moral cognition and moral quality before receiving the education, which naturally leads to a certain degree of cognitive, emotional, volitional and behavioral conflicts between them and social requirements. Therefore, in the process of moral education, educators should start by stimulating the psychological needs of educatees, mobilizing their enthusiasm for acceptance, guiding their correct cognition, and helping them cultivate their will, so that the educatees can actively receive education and play a main role. To encourage them to internalize the moral concepts and ethics required by society into their own concept systems. And ultimately the educatees will externalize the concepts into social behavior. At the same time, whether the educatees agree with and like the educator, and how effective the education content is, will also prompt the educator to adjust the educational content and methods. It can be seen that in the process 
of moral education, the psychological influence of educators and educatees is a twoway interaction. The leading role of the educator and the main role of the educatees are mutually influential and restrictive. In this process, through good communication and interaction between educators and educatees, conflicts can be resolved and a harmonious state can be formed, which is exactly the process of realizing the moral education affinity.

\section{Cultivating the Ways of Moral Education Affinity}

The good effect of moral education affinity is undoubtedly an important factor for the smooth development of moral education. In the process of affinity generation, educators and educatees interact with each other psychologically, with educators playing a leading role and educatees playing a principal role. They complement each other. Therefore, educators should take the initiative to strengthen their own comprehensive quality, according to the psychological mechanism of educatees, actively carry out work according to the corresponding psychological theory, psychological principles and psychological laws, so as to truly place the educatees at the center, as the main focus. Educators should adhere to the close combination of theory and practice, realize the unity of knowledge and practice, promoting the generation of moral education affinity and meeting the needs and expectations of the growth and development of educatees.

\subsection{Paying full attention to the level or change of the needs of educatees}

Firstly, educators respect the individual needs of the educatees. Educatees need different content. Some need spiritual guidance such as ideals and beliefs, while others need specific help with studying, life and interpersonal communication. Therefore, educators should carry out targeted moral education activities taking different people into consideration. In addition, the autonomy of the educatees is increasing day by day, for example, higher requirements are put forward for the truth of the educational content, the scientific nature of educational methods, and the diversity of educational means. If educators are forced to indoctrinate and pressure them, it is bound to cause psychological rejection on the part of educatees, leading to conflicts between the two sides. However, if education can satisfy the independent needs of educatees, it will arouse their enthusiasm for learning. Secondly, educators should strengthen the legitimate needs of educatees. The needs of the educatees with regard to education vary; some are lawful and reasonable, and some are illegal and unreasonable. Educators respect the need to be right and ethical, and on this basis, they constantly strengthen it to provide motivation for their behavior. Thirdly, educators guide educatees to pursue higher level needs. At present, educatees are acquiring more and more things and information. If they cannot make a correct judgment and choice, it is bound to affect the development of their benign needs. Therefore, according to the hierarchy of needs theory, educators can guide them from the pursuit of low-level physiological needs, safety needs and social needs to high-level respect needs 
and self-realization needs.

\subsection{Try to stimulate and strengthen the learning motivation of educatees}

The moral character of educatees will not be formed spontaneously, neither will learning motivation, which entails that educators should follow the formation law of learning motivation and use scientific methods to stimulate educatees' learning motivation. Firstly, educators closely engage with social reality and moral problems to trigger learning needs. Educators should be good at guiding the educatees to pay close attention to the hot topics of morality in real life, and create various situations of moral problems by using psychological situations, so as to arouse the educatees' desire to think and explore, and make them enter the specific learning situation and engage with problems. Secondly, educators stimulate the students' learning motivation by carrying out learning competitions. The incentive method can directly and effectively stimulate the educatees' awareness of being evaluated by others and obtain respect from others through competition, so as to meet their self-esteem and self-developmental needs. Educators can also use the method of strengthening incentives to give timely affirmation, praise and encouragement to the moral consciousness and behavior performance of the educatees in line with social requirements. That is positive reinforcement. We should criticize and punish the bad moral concepts and behaviors of the educatees over time. That is negative reinforcement. Through positive and negative reinforcement, we can improve the cognitive level and moral judgment ability of educatees.

\subsection{Maintaining the principal status and function of educatees}

During in the process of education, we should really consider the needs of educatees, pay close attention to their emotions, help to cultivate their will, promote the externalization of their behaviors, and promote the generation of moral education affinity. Firstly, educators should enhance the quality of life and times of moral education. In response to the needs of educatees, and in accordance with learning psychology and acceptance psychology, the choice of educational content should broaden the horizon of life and times to meet the needs of their development. On the one hand, they should be good at digging out valuable local and additional materials, enhance the sensibility and closeness of teaching content, and make the educatees feel and experience the significance and function of moral education up close. Secondly, educational methods and means should be diverse and dynamic. Traditional indoctrination and preaching have been difficult to adapt to the needs of educatees in the new era. Therefore, educators should actively explore scientific education methods and diversified educational means that meet the physical and mental characteristics and development needs of the educatees, stimulate the potential of students' autonomous learning, and enrich the students' participation and the communication mode between teachers and students with the help of information technology, such as new social media, so as to enhance the attraction of 
moral education.

\subsection{Enhancing the appeal and affinity for the education process through the combination of knowledge and practice}

The process of moral education is a process of unifying knowledge and practice, and also a process of integrating theory with practice. On the one hand, the educatees' acceptance of moral education content is the dialectical unity of cognition and behavior. Cognition is the premise and foundation of behavior, and behavior is the purpose and destination of cognition. Without systematic and complete theoretical study, the educatees cannot form correct cognition and behavior. Therefore, educators need to help and guide them to internalize the moral consciousness and moral norms required by the society into their own moral concepts, to form correct cognition, and then externalize them into social behaviors. On the other hand, moral education is also the unity of theory and practice. The achievement of educational effect depends not only on vivid theoretical teaching, but also on lively practical activities. Through "situational teaching" and specific practical activities, educators can stimulate the motivation for learning and enthusiasm of the educatees, so that they can form correct cognition and get real experience in practice. And practice can promote their understanding of theory and produce new cognition, which can continue to guide practice. It can be seen that only through personal experience can educatees have a sense of gain. Only when they have a sense of gain can they feel the appeal of moral education. Only with the appeal can moral education have affinity.

It should be emphasized that in the process of forming moral education affinity, educators must constantly improve their comprehensive qualities. Educators' optimistic attitude, healthy mood and positive personality strengths are very important for the generation of moral education affinity. Only when educators constantly enhance their moral cognition, improve their professional level and work ability, and enhance their personality quality, can the moral education affinity be generated and maintained, and the actual effect of moral education can be greatly improved by persuading people with virtue, educating people with talents and skills, and moving people with emotion.

\section{References}

Arends R. I. 2005. Learning to Teach. $6^{\text {th }}$ ed. Xi'an, China: Shannxi Normal University Publishing House.

Chapman E. S. \& McGregor S. E. 2002. "Effects of Interpersonal Attraction on Cooperative Learning Outcomes for Secondlyary Level Students," Current Research in Social Psychology 7(18):311-325. 
Deci E. \& Ryan R. 1985. "Intrinsic Motivation and Self-Determination in Human Behavior." New York: Academic Press. DOI:10.2307/2070638.

Garnet D. 2016. "Affinity and Interpretation in Oral Histories of Art Education," International Journal of Research \& Method in Education 40(4):1743-7288. DOI: 10.1080/1743727X.2016.1139081.

Habermas J. 1985. Autonomy and Solidarity. Interviews with Jürgen Habermas, ed. and introduced by P. Dews. London - New York: Verso.

Hasija D., Liou R.-S., \& Ellstrand A. 2020. "Navigating the New Normal: Political Affinity and Multinationals' Post-Acquisition Performance," Journal of Management Studies 57(3). DOI: 10.1111/joms.12545.

Liu P. P., Savitz-Romer M., Perella J., Hill N. E., \& Liang B. 2018. "Student Representations of Dyadic and Global Teacher-Student Relationships: Perceived Caring, Negativity, Affinity, and Differences across Gender and Race/Ethnicity," Contemporary Educational Psychology 54:281-296. DOI: 10.1016/j.cedpsych.2018.07.005.

Li Qu \& Qu Yang. 2019. "Modeling and Analysis on Teacher-Student Relationship," Hindawi. Discrete Dynamics in Nature and Society 1-7. DOI: $10.1155 / 2019 / 5481926$.

Maslow A. H. 1943. “A Theory of Human Motivation," Psychological Review 50:370-396. DOI: $10.1037 / \mathrm{h} 0054346 ; 10.1177 / 0022487118788838$.

Noonan J. 2019. "An Affinity for Learning: Teacher Identity and Powerful Professional Development," Journal of Teacher Education 70(5):526-537.

Pinto M. S. \& Poornananda D. S. 2017. "Affinity of Media: Importance Students Attach to Newspaper, Television and The Internet," Mass Communicator: International Journal of Communication Studies 11(1):9-14. DOI: 10.5958/0973967X.2017.00002.3.

Ren F.U. 2016. "The Construction of a Harmonious Relationship Between Teachers and Students to Improve the Actual Effect of Moral Education," Higher Education of Social Science 11(5):13-17. DOI: 10.3968/9074.

Roeser R., Eccles J., \& Sameroff A. 2017. 'School as a Context of Early Adolescents' Academic and Social Emotional Development: A Summary of Research Findings," Elementary School Journal 100:443-471.

Scherzinger M. \& Wettstein A. 2019. "Classroom Disruptions, the Teacher-Student Relationship and Classroom Management from the Perspective of Teachers, Students and External Observers: A Multimethod Approach," Learning Environments Research 22(1):101-116. DOI: 10.1007/s10984-018-9269-x. 
Zhang Jing (Nanjing), Li Suting (Shanghai)

\title{
Research on Moral Education Affinity from the Perspective of Psychology
}

\begin{abstract}
Moral education affinity has a very important influence on the smooth development of moral education activities and the improvement of educational effectiveness. From the perspective of psychology, the needs and emotions of the educatees are its motivational mechanism, the will of the educatees is its maintenance mechanism, psychological compatibility is its guarantee mechanism, and the learning psychology of the educatees is the reinforcement mechanism. The generation of moral education affinity is the process of educators' active interpersonal attraction, the application of positive psychological effect, the change of educatees' attitude, and the psychological exchange and interaction between educators and educatees. The main way to cultivate moral education affinity is to fully pay attention to the needs or changes of the educatees, make efforts to stimulate and strengthen the learning motivation, maintain the main status and role of the educatees, and enhance the appeal and affinity of the educational process through the unity of knowledge and action.
\end{abstract}

Keywords: moral education affinity; mental process; psychological mechanism; generation of affinity; cultivation of affinity.

Ethics in Progress (ISSN 2084-9257). Vol. 11 (2020). No. 1, Art. \#7, pp. 120-132 Creative Commons BY-SA 4.0

DOI:10.14746/eip.2020.1.7 